\title{
SOBRE CADEIAS DE GÊNEROS
}

\author{
Kennedy Cabral Nobre ${ }^{1}$ \\ Bernardete Biasi-Rodrigues ${ }^{2}$
}

Resumo: Neste ensaio discutimos sobre cadeias de gênero, um agrupamento específico de gêneros discursivos caracterizado pela passagem sistemática e necessária de um gênero a outro(s). Baseados na Sociorretórica de Swales (2004) e na Análise Crítica do Discurso de Fairclough (2001a; 2003), buscamos critérios para caracterização de uma cadeia de gêneros, bem como critérios para sua classificação. Propomos considerar dois tipos especificos de encadeamento genérico: um simples, em que os gêneros todos são produzidos num único domínio institucional; e um complexificado, quando outros dominios institucionais ramificam-se de uma cadeia de gêneros simples preexistente.

Palavras-chave: Gêneros discursivos. Cadeias de gêneros. Dialogismo. Intertextualidade.

\section{INTRODUÇÃO}

A concepção dialógica dos enunciados, ratificada no recorrente axioma bakhtiniano de que "um enunciado é um elo de uma cadeia muito complexa de outros enunciados" (BAKHTIN, 2000, p. 291), é a base para o conceito de cadeia de gêneros (FAIRCLOUGH, 2003; SWALES, 2004) a ser tratada neste ensaio. Mediante o pensamento bakhtiniano concernente ao dialogismo é que se passou a compreender o enunciado não de forma insulada, mas como elo de intrincada e infinita malha historicamente construída; além disso, a dinamicidade inerente ao caráter dialógico da linguagem possibilitou a compreensão de como diferentes formas textuais relacionam-se, por mais inusitada que tal relação possa parecer. De fato, qualquer texto pode originar um ou mais textos materializados em gêneros discursivos que não estejam realmente previstos nas interações mais usuais, assim como qualquer texto pode fazer remissão - consciente, por parte do produtor, ou não - a textos mais próximos ou mais distantes no espaço-tempo; no entanto, interessa-nos especificamente neste trabalho o que se tem comumente

\footnotetext{
1 Doutorando do Programa de Pós-Graduação em Linguística UFC. Email: cabralnobre@yahoo.com.br.

${ }^{2}$ UFC, Professora Associada, doutora em Linguística. † 31/10/2011.
} 
denominado cadeia de gêneros, isto é, as formas de diálogo/relação entre gêneros mais recorrentes e rotineiras, em que já esteja prevista, na abstração de um determinado gênero discursivo, a consequente produção de outro gênero, também determinado. Neste caso o inverso também se aplica, ou seja, nos casos em que certos gêneros de discurso, em sua abstração, estão propensos a 'responder' gêneros discursivos específicos.

Nas cadeias de gêneros - uma forma específica de relação dialógica -, as relações que se estabelecem entre os gêneros que as constituem são tomadas como dadas antes mesmo de sua real produção (materialização textual), diferentemente do dialogismo que, embora constitutivo da linguagem, nos põe diante de uma infinidade de possibilidades que nos leva a generalizações um tanto vagas e imprecisas quanto ao vínculo que determinados gêneros têm entre si. Em suma, a concepção de cadeia dá conta das relações preestabelecidas entre determinados gêneros discursivos, de modo que sua realização textual ratifica esse estado de predisposição; ao passo que a concepção dialógica dos enunciados dá conta das potenciais (e portanto imprevisíveis) relações que textos específicos possam manter, de modo que é preciso verificar cada exemplo em sua singularidade na materialização textual.

Convém salientar, entretanto, que o fato de que em determinados gêneros já está prevista uma relação intrínseca com outros não impede que as inúmeras manifestações textuais desses gêneros efetivamente se interliguem a textos não previstos. Em outras palavras, a organização de determinados gêneros em uma cadeia não anula sua potencial relação com outros textos/gêneros - nem poderia, visto ser seu caráter dialógico constitutivo; assim como também não se anula a possibilidade singular de uma cadeia se 'romper' antes que se materialize em sua totalidade, motivada pelos mais diferentes fatores, sem que esse fato insólito descaracterize uma cadeia; em outras palavras, mesmo que recorrente e previsível, a efetivação de uma cadeia de gêneros não pode ser tomada como obrigatória. 


\section{DAS CADEIAS DE GÊNEROS}

\subsection{A ABORDAGEM DE FAIRCLOUGH}

Inicialmente Fairclough (2001a, p. 166) não fala a respeito de cadeias de gênero, mas sim de cadeias intertextuais para referir-se a um mesmo fenômeno. Esta escolha terminológica justifica-se em decorrência do aparato teórico que estava sendo construído na obra em questão: mudanças nas ordens de discurso em níveis locais e/ou societários são possibilitadas via o contato intertextual entre distintas ordens de discurso, de forma a ser possível aos indivíduos a percepção de assimetrias nas posições de sujeito e, consequentemente, haver a contestação da hegemonia por meio do estabelecimento de uma plataforma de luta, e assim rearticularem-se os elementos de uma dada ordem de discurso. A intertextualidade é, nesse caso, elemento fundamental, pois o autor pressupõe, com base em Bakhtin, AuthierRevuz e Maingueneau, que os textos são linguisticamente heterogêneos no sentido de que são formados por elementos de valores variados e não raro semântica e estilisticamente contraditórios (FAIRCLOUGH, 2001a, p. 133).

$\mathrm{O}$ autor, ao mesmo tempo em que acomoda categorias preexistentes sobre intertextualidade (manifesta e constitutiva, por exemplo), define duas perspectivas de olhar o fenômento intertextual: o viés paradigmático, que diz respeito à escolha de elementos de uma ordem de discurso que vão efetivamente materializar-se em textos (gênero, discurso, estilo, principalmente, mas também registro e tipos de atividade), e o viés sintagmático, que se relaciona aos textos antecedentes e subsequentes numa rede textual.

Uma forma específica de relação intertextual sintagmática são as cadeias intertextuais, definidas como "séries de tipos de texto que são transformacionalmente relacionados umas às outras, no sentido de que cada membro das séries é transformado em um outro ou mais, de forma regular e previsível" (FAIRCLOUGH, 2001a, p. 166). Observemos que, neste primeiro momento, o autor não fala em gêneros, tanto por a discussão estar vinculada à intertextualidade horizontal/sintagmática, 
quanto por considerar que a 'transformação'3 de um texto em outro guarda resquícios intertextuais de níveis diferençados.

Posteriormente (FAIRCLOUGH, 2003), a expressão cadeias intertextuais é substituída por cadeias de gêneros, mas a definição é praticamente a mesma: "séries de tipos de texto que são transformacionalmente relacionadas umas às outras, no sentido de que cada membro das séries é transformado em um outro ou mais, de forma regular e previsível" (FAIRCLOUGH, 2001a, p. 166) e "diferentes gêneros que se ligam regularmente, envolvendo transformações ${ }^{4}$ sistemáticas de gênero para gênero" (FAIRCLOUGH, 2003, p. 31).

Pode-se argumentar, a respeito da primeira definição, que a expressão tipos de texto parece remeter a gêneros discursivos e que gênero, utilizado após refinamento teórico do autor, substitui melhor, em termos de definição, tipos de texto, mas verifica-se que o núcleo da concepção é o mesmo: regularidade, previsibilidade, sistematicidade na passagem de um texto/gênero a outro. Ademais, se determinado texto é transformado noutro ou em mais, de maneira regular, sistemática e previsível, é porque tal texto apresenta um mínimo de traços necessários e estáveis a partir dos quais é possível categorizá-lo sob um rótulo genérico.

Assim, não há diferença conceitual entre cadeias intertextuais e cadeias de gêneros, mas utilizaremos a segunda denominação tanto para usar a expressão mais recente do autor, quanto por acreditar que é mais conveniente falar de gênero que de intertexto, visto ser aquele conceito mais bem definido que este. Outro critério definidor de cadeias de gêneros subjacente às proposições diz respeito a um agrupamento inevitável de gêneros (séries de tipos de texto, na primeira definição; diferentes gêneros, na segunda), comungando com a perspectiva de Swales (2004, discutida a seguir) de que as cadeias de gêneros são uma forma específica de agrupamento genérico.

\footnotetext{
${ }^{3}$ Em se tratando de uma noção que se confunde com a de intertextualidade, cremos que o termo 'transformação', ainda que empregado metaforicamente, não seja o mais adequado, uma vez que pode confundir-se com estratégias de parafrasagem, por exemplo. A nosso ver, os gêneros de uma cadeia são produzidos não pela transformação de seu(s) precedente(s), ainda que muito de seu teor informativo seja alimentado com dados constantes no(s) gênero(s) que o(s) antecede $(\mathrm{m})$.

4 Do original: "different genres which are regularly linked together, involving systematic transformations from genre to genre".
} 
Cabe ressaltar aqui os critérios definidores de uma cadeia de gêneros: a regularidade, previsibilidade e sistematicidade na passagem de um gênero em outro. Fairclough (2001a, p. 166-167) chama a atenção para isso:

Dado o considerável número e a variedade de diferentes tipos de textos, poderia haver, em princípio, um imenso e de fato interminável número de cadeias intertextuais entre eles. Entretanto, o número das cadeias reais é provavelmente bastante limitado: as instituições e as práticas sociais são articuladas de modos particulares, e esse aspecto da estruturação social limita o desenvolvimento das cadeias intertextuais.

Neste excerto, fica inegável a relação que há entre cadeias de gêneros e as práticas de uma instituição, daí o critério de sistematicidade estar também vinculado. Caso não seja considerada a passagem regular de um gênero a outro(s), o conceito acaba se confundindo com o dialogismo bakhtiniano e se torna inoperante, dado o caráter constitutivo do dialogismo.

\subsection{A ABORDAGEM DE SWALES}

Em trabalho posterior aos de Fairclough (2001a; 2003), Swales (2004) tece uma discussão acerca de cadeias de gêneros, estabelecendo critérios semelhantes aos de Fairclough, e acrescentando outros aspectos. A questão das cadeias de gêneros, para Swales, se insere num debate que envolve os diferentes modos de relação que se estabelecem entre gêneros, no sentido de compreender melhor como se organizam as práticas discursivas. Nesse contexto, o autor desenvolve o conceito de constelação, que diz respeito a formas distintas de agrupamentos genéricos que podem se vincular em termos de hierarquias, cadeias, grupos e redes. No que se refere especificamente a cadeias, o autor comenta que a relação que se dá entre gêneros nessa perspectiva é de ordem cronológica, "especialmente quando um gênero é necessariamente 
antecedente de outro" (SWALES, 2004, p. 18, grifo nosso) ${ }^{5}$, de forma que tal caracterização dialoga com os critérios de previsibilidade e regularidade defendidos por Fairclough (2001a). O autor ainda sustenta que algumas cadeias envolvem poucos gêneros, e portanto são curtas, mas que uma característica comum a qualquer agrupamento dessa natureza é a presença de um gênero 'oficial', o que sugere uma escala de importância subjacente aos gêneros de uma cadeia - uma provável influência do primeiro tipo de constelação discutido pelo autor, a bierarquia, que cuida dos diferentes graus de importância que uma determinada área ou comunidade discursiva lega aos gêneros que produz.

Particularmente contestamos tal escala de importância, uma vez que assumimos que cada gênero de uma cadeia é dependente do seu precedente e indispensável ao consequente, de modo que a não realização isolada de um gênero poderá acarretar a não realização integral de uma cadeia e assim causar interrupções numa prática sóciohistoricamente estabilizada. Contudo, não podemos negar o prestígio social que é transferido a certas práticas discursivas em detrimento de outras, criando, desse modo, uma forma de hierarquia relacionada a crenças sociais, o que não compromete a negação da hierarquia que defendemos.

Swales (2004) utiliza a cadeia de gêneros estudada por Räisänen (1999) - de quem se apropriou do termo, conforme o próprio autor esclarece - para exemplificar a relação necessária e cronológica entre gêneros. Os gêneros que constituem essa cadeia em específico são do domínio institucional acadêmico, mas Swales (2004) focaliza o artigo de apresentação em conferência (conference presentation paper - CPP), numa clara consideração acerca de uma possível organização hierárquica, isto é, todos os gêneros que constituem a cadeia apresentada são produzidos em função do CPP e são nomeados a fim de se ter uma noção a respeito do funcionamento das práticas que envolvem o gênero que é privilegiado.

\footnotetext{
${ }^{5}$ Do original: "especially when one genre is a necessary antecedent for another".
} 
Figura 1 - Cadeia de gêneros em Segurança de Acidentes:

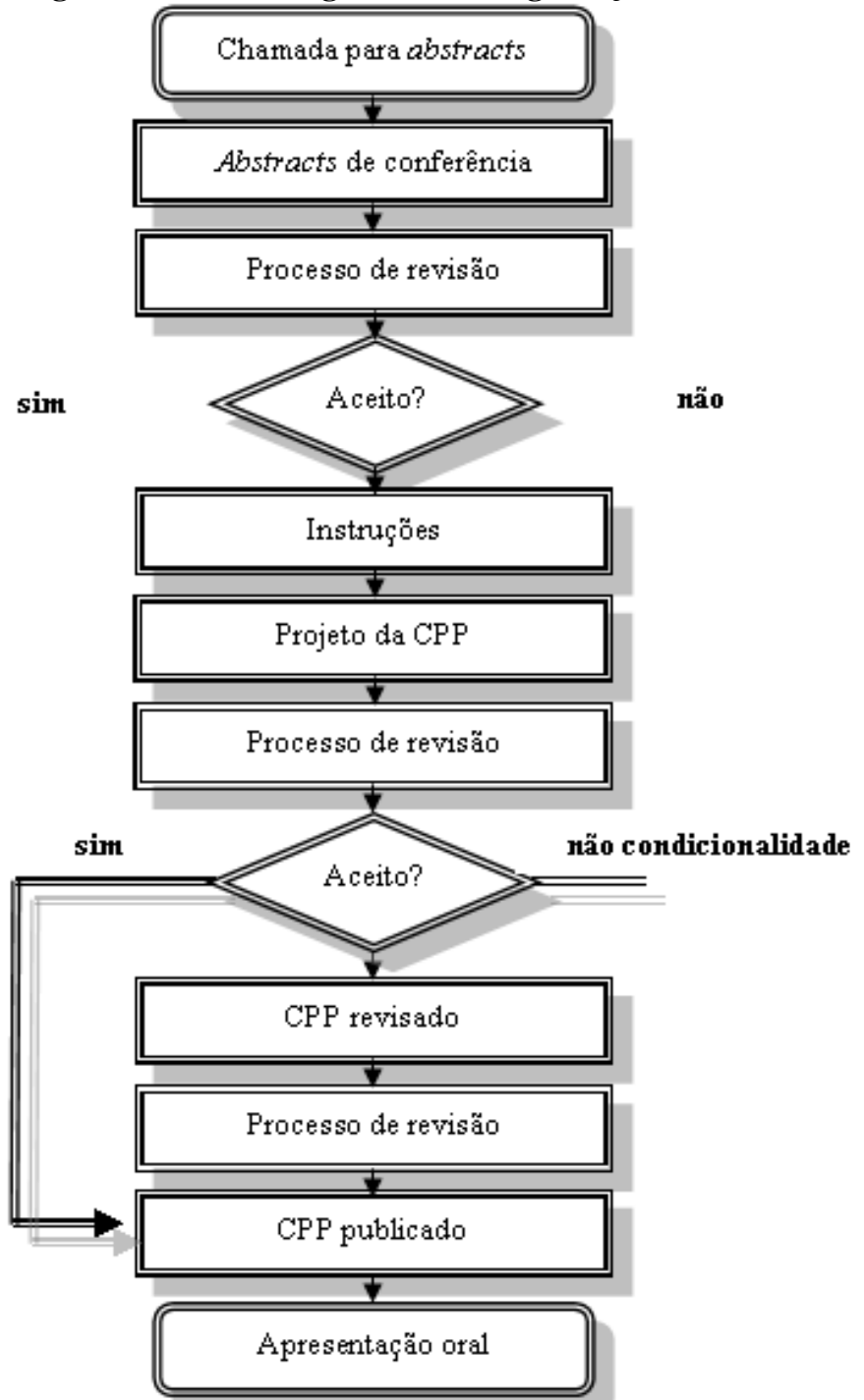

Fonte: Räisänen (1999 apud Swales, 2004, p. 19). ${ }^{6}$

${ }^{6}$ A tradução dos textos que compõem essa Figura é de Araújo (2006).

NOBRE; BIASI-RODRIGUES - Sobre cadeias de gêneros 
Consoante se pode observar na Figura 1, o gênero que desencadeia os demais é a chamada para abstracts, que gera a produção de resumos que, posteriormente, serão avaliados por uma comissão específica. Após avaliação, serão emitidas cartas de aceite, acompanhadas por uma série de instruções a respeito das regras para produção de artigos. Observam-se duas etapas distintas de revisão antes da publicação do artigo e de sua posterior apresentação oral em um evento acadêmicocientífico. Convém ressaltar que a cadeia acima foi desenhada partindo da perspectiva do indivíduo que submete um trabalho para publicação e apresentação e não do ponto de vista da instituição onde se desenvolvem os gêneros, e onde são definidas todas as regras para sua submissão, publicação e apresentação. Talvez por essa razão, o autor afirmou que todos os gêneros se subordinam ao artigo, já que o ponto de vista é de seu produtor.

Por conta dessa perspectiva (adotada por Räisänen), Swales discute acerca da inclusão de gêneros 'fechados' (occluded - termo cunhado por Swales, 1996), na cadeia, para designar as práticas discursivas realizadas não publicamente, como, no caso em foco, avaliação dos artigos, discussão entre examinadores, etc. Tais gêneros (denominados práticas) teriam inevitavelmente de entrar na configuração da cadeia uma vez que, adotando os critérios de Fairclough (2001a), são previsíveis e regulares na instância responsável pelo evento onde os trabalhos serão apresentados.

Em síntese, pode-se dizer que o ponto de convergência entre as duas perspectivas é um agrupamento de gêneros que mantêm entre si uma relação regular, previsível (FAIRCLOUGH, 2001a), sistemática (FAIRCLOUGH, 2003), necessária e cronológica (SWALES, 2004), quando da passagem de um gênero a outro, configurando-se uma cadeia de gêneros. Passemos, a seguir, à proposta de refinamento de tais critérios discutidos na pesquisa de Nobre (2009).

\section{REDISCUSSÃO DOS CONCEITOS}

Os critérios elencados há pouco pressupõem um critério maior relacionado ao gênero discursivo que se encontra numa relação regular e necessária na produção de outro(s) gênero(s). Em outras palavras, já está prevista, em maior ou menor grau, no propósito comunicativo de 
determinado gênero integrante de uma cadeia, a posterior realização de outro, numa clara relação de contínua complementaridade da cadeia, principalmente em se tratando de cadeias simples. Assim, uma pergunta requer uma resposta; uma saudação, outra, etc. Há gêneros, contudo, cujo propósito os relaciona a outros sem necessariamente haver o estabelecimento de cadeias. É o caso de resumos, resenhas, cartas do leitor, etc., que estão claramente remetendo a textos anteriores, mas não se pode dizer, por exemplo, que toda obra publicada será resenhada.

Feita esta ressalva a respeito do propósito como pressuposto de uma cadeia, propomos distinguir dois tipos de cadeia de gêneros: as simples, que são produzidas no âmbito de um único domínio institucional; e as complexas, cuja relação ultrapassa as fronteiras de uma dada instituição. A base para tal distinção encontra-se em Fairclough (2001a), o qual, sem se preocupar em estabelecer uma classificação em torno das cadeias de gêneros, afirma que "um simples exemplo seria a cadeia que liga as consultas médicas com os registros médicos: os médicos rotineiramente transformam as primeiras nos últimos" (p. 166), e posteriormente declara que

as cadeias intertextuais podem ser muito complexas [...] Um discurso importante do presidente Gorbachev será transformado nos textos da mídia de vários tipos em cada país do mundo, em reportagens, análises e comentários por diplomatas, em livros e artigos acadêmicos, em outros discursos que o parafraseiam, o elaboram, respondem a ele, e assim por diante. (p. 167).

Não é difícil atestar que o uso dos vocábulos simples e complexos nos excertos acima não tem o propósito tipológico, mas sim um valor qualitativo que fomenta a argumentação do autor. Entretanto, em nossa pesquisa de mestrado, ao estudar a cadeia de gêneros da qual anúncios escolares fazem parte, verificamos a pertinência de uma discriminação terminológica assentada em critérios respeitantes à realização institucional dos gêneros que a constituem.

Outro aspecto que é importante discutir é que algumas abordagens vinculam os gêneros discursivos a tipos de atividade específicos (FAIRCLOUGH, 2001a) e a uma determinada ação social 
(MILLER, 2009; BAZERMAN 2009; FAIRCLOUGH, 2003). Nesse caso, as cadeias de gêneros inevitavelmente passam a estar vinculadas a uma série de atividades e ações sociais. Entretanto, ratificamos nossa posição de que todo gênero implica uma ação ou várias ações, mas nem toda ação é concretizada por meio de um gênero discursivo específico. Desse modo, convém falar em cadeias de práticas, expressão originalmente cunhada por Meurer (2004, p. 139): "Em uma analogia ao conceito cadeias de textos (BAKHTIN, 1992), sugiro a incorporação à LSF e à ACD do termo cadeias de práticas para indicar que cada prática social sempre se relaciona a outras práticas no mesmo contexto e/ou em outros contextos". $\mathrm{Na}$ passagem, fica patente que o conceito do autor está intimamente ligado à questão do dialogismo e, a nosso ver, é bastante próxima do conceito de redes de práticas (CHOULIARAKI; FAIRCLOUGH, 1999), mas nesta pesquisa atrelamos a este conceito os critérios elencados para cadeias de gêneros, a saber: previsibilidade, regularidade, sistematicidade, necessidade, cronologia.

Em analogia à dialética entre o discurso e as práticas sociais, acreditamos que haja também uma dialética entre as cadeias de práticas e as cadeias de gêneros, isto é, as práticas sociais e discursivas altamente institucionalizadas criam padrões de comportamento que se refletem nas práticas textuais e acabam criando cadeias de gêneros. Todos os grandes domínios institucionais, como a Educação, a Medicina, o Direito, etc. possuem exemplares de cadeias de gêneros que, por sua vez, reforçam as práticas sociais encadeadas. Assim, subjacente a qualquer cadeia de gêneros, seja ela simples ou complexa, há uma cadeia de práticas. Tomando o exemplo de Fairclough (2001a, p. 167), em que a consulta médica antecede o registro médico, pode-se acrescentar uma série de procedimentos não discursivos que caracterizam a ordem de discurso onde é realizada a cadeia de gêneros em foco, tais como a intervenção cirúrgica resultante de uma consulta, ou a aquisição de medicamentos prescritos e sua posterior ingestão conforme posologia indicada. Em suma, defendemos que qualquer cadeia de gêneros demanda a existência de uma cadeia de práticas, no sentido de que aquela está contida nesta, pois algumas práticas encadeadas, mas não todas, são realizadas por meio de recursos verbal-semióticos, dos quais se vislumbra uma série de gêneros discursivos. 


\subsection{SOBRE AS CADEIAS SIMPLES}

As cadeias simples mais evidentes são aquelas cujos gêneros/práticas que as constituem são produzidos/realizadas num domínio institucional particular e contribuem, portanto, para caracterizálo, sendo frutífero distinguir em cada cadeia simples uma série de gêneros situados (FAIRCLOUGH, 2003, p. 68-70). Elas também estão intimamente relacionadas com o conceito de ordem de discurso de Fairclough (2001a; 2001b; 2003), pois, enquanto esta diz respeito a uma totalidade de práticas (gêneros, discursos, estilos) de uma instituição, aquela diz respeito a uma totalidade de práticas regulares de uma instituição, organizadas obedecendo a uma lógica funcional.

Obviamente não se deve vincular cadeias simples unicamente a instituições. Um bom exemplo de gêneros quotidianos que se encadeiam é o que a Análise da Conversação tem chamado de pares adjacentes ou conversacionais, tais como saudação-saudação, pedido de desculpaperdão e pergunta-resposta ${ }^{7}$, assim como há gêneros em que está prevista sua contínua reprodução, as cartas-corrente, formando uma ininterrupta cadeia de um único gênero. Todavia, se verifica que as cadeias simples são mais nitidamente percebidas nas práticas institucionais, as quais são, em sua maioria, materializadas em textos identificados como gêneros discursivos. Além disso, observa-se também, em cadeias simples de instituições, a existência de gêneros reguladores tais como regimentos, leis, regulamentos, editais, cuja função é apresentar normas que regem o funcionamento das práticas de uma dada instituição, nas quais se percebe a 'configuração' da disposição de gêneros e práticas que a integram.

Quanto a essa distribuição organizacional de gêneros e práticas, podemos afirmar que, além do aspecto cronológico previsto por Swales (2004), verifica-se uma relação (crono)lógica, ou seja, além de uma mera

\footnotetext{
${ }^{7}$ Considerando a alternância dos sujeitos falantes como critério bakhtiniano para acabamento dos gêneros, defende-se cada par desses elementos como tais, principalmente em se tratando de estruturas conversacionais em que não há um propósito comunicativo maior subjacente a toda a conversação, como a entrevista ou o debate - estes sim entendidos como gêneros produzidos em circunstâncias culturalmente mais complexas.
} 
localização temporal, há uma localização funcional de cada gênero/prática constitutivo/a de uma cadeia, uma vez que a sua posição não é intercambiável, dada a dependência que determinado gênero/prática possui em relação aos gêneros/práticas imediatamente adjacentes.

É possível fazer uma analogia dos gêneros e práticas que se encadeiam numa instituição com o aspecto disciplinar apontado por Foucault (2008), isto é, percebemos que as cadeias são processos disciplinares institucionalizados na medida em que são estabelecidas normas internas para o bom funcionamento das práticas de uma dada ordem de discurso. Assim, cada gênero/prática funciona como uma engrenagem de um sistema cujo êxito depende do êxito individual de cada componente. Desse modo, percebe-se que cada gênero/prática é realizado/a por indivíduos que têm prerrogativas para tal. Observa-se também, por parte de indivíduos que desejam se incluir numa ordem de discurso, a adequação de suas práticas em conformidade com as normas previamente estabelecidas. Dentro de limites institucionalizados, quem não possuir a competência genérica relativa aos gêneros produzidos numa instância específica acabará por se ver excluído da comunidade social em questão, ou, ao menos, não desfrutará dos mesmos privilégios de quem detiver a competência genérica exigida.

É também proveitosa a relação entre cadeias simples e comunidades discursivas (SWALES, 1990; 2009), dada a sua vinculação a instituições. Para a definição e o reconhecimento de uma comunidade discursiva, Swales (1990) enumera seis características ${ }^{8}$, a saber: conjunto de objetivos públicos em comum, mecanismos de comunicação compartilhados, mecanismos de promoção de participação e feedback, compartilhamento de gêneros e conhecimentos, compartilhamento de léxico específico e relação hierárquica entre membros mais experientes e membros iniciantes. Em maior ou menor grau, todas essas características podem ser identificadas em comunidades discursivas em que se realizam cadeias simples.

\footnotetext{
${ }^{8}$ Retomados em Swales (2009).
} 
Os objetivos públicos comuns dos usuários podem-se relacionar a um objetivo geral institucional que põe em funcionamento as práticas de uma dada instituição de maneira integral, de forma que, se a produção de um gênero depende da produção de um antecedente, é possível vislumbrar uma causa subjacente que alimenta todas as práticas (e aqui se incluem os gêneros) de uma instituição. No se que refere às quatro características seguintes apontadas (mecanismos de intercomunciação entre os membros de uma comunidade discursiva, mecanismos de promoção de participação e feedback, conhecimento e compartilhamento de gêneros e léxico específico), ressaltamos que elas estão diretamente vinculadas aos gêneros e práticas que constituem uma cadeia, no sentido de que para a passagem de um gênero/prática a outro/a é necessária a integração desses quatro critérios. Em relação à hierarquia entre participantes iniciantes e experientes, nota-se que o ingresso institucional de um membro novato requer o 'letramento' (em sentido amplo) das práticas sociodiscursivas efetuadas no interior das instituições, assim como da subordinação às regras convencionadas, sob o risco de sanções. Todavia, dependendo da dimensão institucional, cada indivíduo pode não ter a noção do todo, ou seja, o indivíduo pode ter ciência somente das práticas realizadas em seus contextos mais imediatos, isto é, das práticas imediatamente antecedentes - às quais se subordina - e imediatamente subsequentes - as quais lhe são dependentes. Nesse caso, há uma relação de exaustividade, cada produtor é responsável por um número limitado de gêneros e práticas.

Deve ser feita a ressalva de que nem sempre que houver uma cadeia simples haverá necessariamente uma comunidade discursiva como os gêneros primários (BAKHTIN, 2000) que se encadeiam, mas acreditamos que há uma tendência em se estabelecerem cadeias de gêneros e práticas como regras de condução de atividades quanto mais estas forem institucionalizadas, perfazendo-se, nisto, uma comunidade discursiva.

Por fim, não se pode afirmar que as cadeias simples são estruturas engessadas. Ainda que seja possível mapear as práticas de uma dada ordem de discurso numa disposição em cadeia, afirmamos que, 
consoante a dialética entre eventos e estruturas (FAIRCLOUGH, 2001a; 2001b; 2003), a organização de atividades de uma dada instituição em gêneros e práticas interligados é passível de mudanças motivadas pela contestação das convenções, no sentido de viabilizar o funcionamento institucional, mas deixando claro que não é qualquer indivíduo que tem poder para promover a execução de uma mudança estrutural.

\subsection{SOBRE A COMPLEXIFICAÇÃO DE CADEIAS SIMPLES}

As práticas sociodiscursivas regulares, sistemáticas e previsíveis, de uma dada instituição, podem servir aos interesses de instituições alheias, motivando, desse modo, o fenômeno de complexificação de uma cadeia simples. Pode-se afirmar, então, que, a priori, não existem cadeias complexas. Cadeias simples, ou seja, práticas sociodiscursivas materializadas na produção sequencial de gêneros e práticas específicos num dado âmbito institucional são, na verdade, complexificadas por meio de práticas discursivas regulares de domínios institucionais que porventura mantenham uma relação de intercontextualidade ${ }^{9}$ (MEURER, 2005) com o lócus institucional onde a cadeia simples se realiza.

Assim, é a relação intercontextual que possibilita a um determinado domínio institucional associar-se às práticas de outro, complexificando uma cadeia simples preexistente. É o que ocorre com o exemplo dado por Fairclough (2001a, p. 167), em que o discurso de um chefe de Estado - gênero situado no domínio institucional político alimenta regular e sistematicamente a produção de diversos gêneros do domínio da imprensa e do domínio científico-acadêmico.

Quando uma cadeia simples é complexificada, verifica-se que o propósito do gênero que origina a complexificação é redimensionado. $\mathrm{O}$ discurso de um chefe de estado pode ser de teor diplomático, por exemplo, mas inserido no âmbito jornalístico ou acadêmico passa a ser investido ideologicamente pelas crenças relativas a esses domínios específicos.

\footnotetext{
${ }^{9}$ Intercontextualidade "é a condição em que dois ou mais contextos se interligam e interpenetram em uma determinada prática social. Na intercontextualidade um contexto é 'levado' para outro contexto e dá-se o compartilhamento de características de ambos.” (MEURER, 2005, p. 135).
} 
A motivação para a complexificação de uma cadeia simples pode ser explicada por relações de poder e lutas hegemônicas. Fairclough (2001a) define hegemonia como uma liderança, parcial e temporária, que uma das classes da sociedade detém sobre as demais nos domínios econômico, político, cultural e ideológico. Todavia, é necessário esclarecer que esta liderança não implica uma dominação, mas sim uma integração entre classes dominantes e subalternas que se opera por meio de alianças e concessões ideológicas, fato que a torna um constante palco de lutas focalizadas nos pontos em que a instabilidade das relações é mais nítida. É importante ressaltar que essas lutas visam não só o rompimento das relações de poder, mas também a sua construção, manutenção e/ou reorganização. Logo, o papel da hegemonia torna-se importante, pois desperta a atenção da população para níveis particulares da cultura, fato que torna tanto a prática hegemônica quanto a luta hegemônica pontos essenciais das práticas discursivas.

Fairclough (2001a) apresenta quatro conceitos para hegemonia: 1) "liderança tanto quanto dominação nos domínios econômico, político, cultural e ideológico de uma sociedade" (p. 122), critério facilmente perceptível nos exemplos em foco: a transformação do discurso de um chefe de estado em notícias revela o interesse de uma determinada empresa jornalística em buscar o prestígio do público em detrimento ou não das demais empresas; 2) "poder sobre a sociedade como um todo de uma das classes economicamente definidas como fundamentais em aliança com outras forças sociais, mas nunca atingido senão parcial e temporalmente, como um 'equilíbrio instável"' (p. 122), donde se percebe que a complexificação de uma cadeia não se dá isoladamente, isto é, de uma única instituição para outra; 3) "a construção de alianças e a integração muito mais do que simplesmente a dominação de classes subalternas, mediante concessões ou meios ideológicos para ganhar seu consentimento" (p. 122), a partir do que percebemos entre as distintas instituições que complexificam a cadeia simples de outra, a criação efetiva de alianças; e 4) "um foco de constante luta sobre pontos de maior instabilidade entre classes e blocos para construir, manter ou romper alianças e relações de dominação/subordinação, que assume formas econômicas, políticas ou ideológicas" (p. 122), postulado este corroborado na contínua reestruturação e rearticulação das convenções de produção dos gêneros constituintes de cadeias complexificadas. 
O critério de intertextualidade é primordial para o reconhecimento de uma relação entre textos produzidos em instâncias distintas, ainda que os critérios básicos para a caracterização de uma cadeia (simples ou complexa) sejam a previsibilidade e a regularidade, pois somente por meio destes é possível distinguir o encadeamento de gêneros (e práticas) das noções mais abrangentes de dialogismo/intertextualidade. Quanto aos critérios de reconhecimento e identificação de uma cadeia complexa, é necessário alertar que, todavia, durante a complexificação de uma cadeia simples, inicialmente não existe o critério de previsibilidade, pois não é propósito do gênero de origem a produção de outro(s) gênero(s) que porventura se lhe(s) encadeie(m). É em decorrência de determinada regularidade, perceptível temporalmente através das práticas que envolvem a produção, distribuição e consumo de um gênero que se associa a uma cadeia simples, que se pode falar em previsibilidade. É uma previsibilidade, contudo, relacionada não ao gênero de origem, mas às práticas sociodiscursivas estabilizadas em determinado tempo $\mathrm{e}$ espaço. Em suma, da regularidade, observa-se a previsibilidade.

\section{CONSIDERAÇÕES FINAIS}

Sumarizando a ligação que os gêneros e práticas mantêm entre si em cadeias simples ou em cadeias complexificadas, podem ser feitas analogias metafóricas, ao se afirmar que a relação entre os constituintes de uma cadeia simples é simbiótica, uma vez que sua associação tem por finalidade o benefício mútuo, e que todos os gêneros e práticas fazem parte de um mesmo organismo e caminham em direção ao seu bom funcionamento. Em contrapartida, a relação entre gêneros e práticas em uma cadeia complexificada é quase sempre parasitária - não no sentido de que uma provoca o malefício da outra, mas no sentido de que nem sempre o benefício é recíproco. Entretanto, dada a regularidade das cadeias complexificadas, é possível que, a longo prazo, as instituições que sofrem a 'parasitação' se beneficiem ou busquem uma forma de se beneficiar de tal estado de coisas. 
Por fim, acreditamos que a importância do estudo deste fenômeno repousa no fato de ele ser revelador de como as práticas sociais são realizadas também por via de práticas discursivas e, em se tratando especificamente de encadeamentos genéricos, como as regularidades das práticas discursivas apontam para sistemas organizados cuja função é disciplinadora assim como mostram como as práticas regulares de uma instituição podem servir de interesse a outra(s).

\section{REFERÊNCIAS}

ARAÚJO, J. C. Os chats: uma constelação de gêneros na internet. 2006. 314 f. Tese. (Doutorado em Lingǘstica) - Universidade Federal do Ceará, Fortaleza, 2006.

BAKHTIN, M. [1979] Estética da criação verbal. Tradução a partir do francês por Maria Ermantina Galvão. 3. ed. São Paulo: Martins Fontes, 2000.

BAZERMAN. C. [2004]. Atos de fala, gêneros textuais e sistemas de atividades: como os textos organizam atividades e pessoas. In: DIONÍSIO, A. P.; HOFFNAGEL, J. C. (Orgs.). Gêneros textuais, tipificação e interação. 3. ed. São Paulo: Cortez, 2009. p. 19-46.

CHOULIARAKI, L.; FAIRCLOUGH, N. Discourse in late modernity: rethinking critical discourse analysis. Edinburgh: Edinburgh University Press, 1999.

FAIRCLOUGH, N. [1992]. Discurso e mudança social. Brasília: Editora da UnB, 2001a.

- [1993]. Análise crítica do discurso e a mercantilização do discurso público: as universidades. Trad. de Célia Magalhães. In: MAGALHÃES, C. (Org.) Reflexões sobre a Análise Crítica do Discurso. Belo Horizonte: Faculdade de Letras - FALE, UFMG, 2001b. p. 31-81.

. Analyzing discourse: textual analysis for social research. London, New York: Routledge, 2003.

FOUCAULT, M. [1975]. Vigiar e punir: nascimento da prisão. Tradução de Raquel Ramalhete. 35. ed. Petrópolis, RJ: Vozes, 2008.

MILLER, C. [1984] Gênero como ação social. In: Gênero textual, agência e tecnologia. Tradução de Judith Chambliss Hoffnagel. Recife: Ed. Universitária de UFPE, 2009. p. 21-44. 
MEURER, J. L. Ampliando a noção de contexto na Linguística SistêmicoFuncional e na Análise Crítica do Discurso. Linguagem em (Dis)curso, Tubarão, v. 4, n. esp., p. 133-157, 2004.

NOBRE, K. C. Para uma concepção ampliada de cadeia de gêneros. 2009. 95f. Dissertação (Mestrado em Linguística) - Programa de pós-graduação em Linguística, Universidade Federal do Ceará, Fortaleza, 2009.

SWALES, J. M. Genre analysis: English in academic and research settings. Cambridge: Cambridge University Press, 1990.

Occluded genres in the academy: the case of submission letter. In: VENTOLA, E.; MAURANEN, A. (Orgs.). Academic writing: intercultural and textual issues. Amsterdam: John Benjamins, 1996.

Research genres: explorations and applications. New York:

Cambridge University Press, 2004.

[1992] Repensando gêneros: nova abordagem ao conceito de comunidade discursiva. In: BEZERRA, B. G.; BIASI-RODRIGUES, B.; CAVALCANTE, M. M. (Orgs.) Gêneros e sequências textuais. Recife: Edupe, 2009. p. 197-220.

Recebido em: 08/08/2011. Aprovado em: 21/04/2012.

Title: About genre chains

Authors: Kennedy Cabral Nobre; Bernardete Biasi-Rodrigues

Abstract: In this essay we discuss genre chains, a specific grouping of discursive genres characterized by the systematic and necessary passage of a genre into other(s). Based on Swales' (2004) Sociorethoric and Fairclough's (2001a, 2003) Critical Discourse Analysis, we search for criteria for the characterization of genre chains, as well as for their classification. We propose to consider two specific types of genre chains: a simple one, in which all genres are produced under a single institutional scope, and a complexified one, when other institutional domains branch from a preexisting simple genre chain.

Keywords: Discursive genres. Genre chains. Dialogism. Intertextuality.

Titulo: Sobre cadenas de géneros

Autor: Kennedy Cabral Nobre; Bernardete Biasi-Rodrigues

Resumen: En este ensayo discutimos sobre cadenas de género, una agrupación específica de géneros discursivos caracterizado por el pasaje sistemático y necesario de un género a otro(s). Basados en la Sociorretórica de Swales (2004) y en el Análisis Crítico del Discurso de Fairclough (2001a; 2003), buscamos criterios para caracterización de una cadena de géneros, bien como criterios para su clasificación. Proponemos considerar dos tipos especificos de encadenamiento genérico: uno sencillo, en el que los géneros todos son producidos en un único dominio institucional; y uno compleificado, cuando otros dominios institucionales se ramifican de una cadena de géneros sencillos preexistente.

Palabras-clave: Géneros discursivos. Cadenas de géneros. Dialogismo. Intertextualidad. 